\title{
Interceptação de Phoma exigua var. foveata, Praga Exótica e Quarentenária para o Brasil, em Germoplasma de Batata Procedente da França
}

\author{
Marta A.S. Mendes, Araílde F. Urben, Alaíde S. Oliveira \& Vera Lúcia A. Marinho \\ EMBRAPA Recursos Genéticos e Biotecnologia, Cx. Postal 02372, CEP 70770-900 Brasília, DF, Brasil, \\ e-mail: martamen@cenargen.embrapa.br
}

(Aceito para publicação em 19/12/2006)

Autor para correspondência: Marta A.S.Mendes

\begin{abstract}
MARTA A.S. MENDES, ARAÍLDE F. URBEN, ALAÍDE S. OLIVEIRA \& VERA LÚCIA A. MARINHO. Interceptação de Phoma exigua var. foveata, praga exótica e quarentenária para o Brasil, em germoplasma de batata procedente da França. Fitopatologia Brasileira 31:601-603. 2006.
\end{abstract}

\begin{abstract}
RESUMO
No Laboratório de Quarentena Vegetal da Embrapa Recursos Genéticos e Biotecnologia, foram realizadas análises fitossanitárias em tubérculos de batata, introduzidos no país para pesquisa, procedentes da França. Alguns desses tubérculos, em exame direto sob microscópio estereoscópio, apresentaram lesões deprimidas de aspecto encharcado, coloração marromarroxeada, casca amolecida e picnídios negros sobre as lesões. Em lâminas, sob microscópio de luz, foram observadas características morfológicas do fungo Phoma exigua var. foveata, praga exótica e de quarentena A1 para o Brasil. Para o teste de patogenicidade foram utilizados tubérculos sadios de batata inoculados com cultura pura do fungo isolado dos tubérculos sintomáticos. Sintomas de apodrecimento foram observados após 3 dias da inoculação, evoluindo até o $8^{\circ}$ dia, quando o fungo foi re-isolado dessas lesões, em BDA, e confirmado o agente etiológico da doença. Os tubérculos apresentando sintomas foram incinerados e aqueles aparentemente sadios foram tratados com fungicida sistêmico, plantados em quarentenário por duas gerações e re-analisados. Após confirmação da sanidade dos tubérculos, os mesmos foram enviados ao requisitante.
\end{abstract}

Palavras-chave adicionais: Serviço fitossanitário, controle de qualidade, quarentena, lista A1 Brasil

\begin{abstract}
Interception of Phoma exigua var. foveata, an exotic quarantine pest for Brazil, in potato germplasm originating in France

Potato tubers from France and introduced to Brazil for research purposes were subjected to phytosanitary analysis at the Quarantine Laboratory of Embrapa Genetic Resources and Biotechnology (Cenargen). Some of the tubers showed sunken, water-soaked, brownish-purple lesions, with soft skin, and black pycnidia were visible in the lesions using a stereomicroscope. Examination of the fungal structures on microscope slides using light microscopy demonstrated that the fungus had the morphology of Phoma exigua var. foveata, an A1 quarantine pest for Brazil. Pathogenicity tests were carried out inoculating healthy potato tubers with a pure culture of the fungus. Rot symptoms were observed 3 days after inoculation and progressed until 8 days. The fungus was re-isolated from the lesions on potato dextrose agar, confirming that the fungus was the etiological agent of the disease. The tubers that were symptomatic were incinerated, and the other healthy-looking tubers were treated with a systemic fungicide, cultivated under quarantine for two generations, and then reanalyzed. After confirming that they were free of the pathogen, the tubers were sent to their destination solicitor.
\end{abstract}

Additional keywords: Phytosanitary Service, quality control, quarantine, Brazil Al list

A maioria dos produtos que faz parte da alimentação dos brasileiros é de origem exótica, embora o Brasil seja o país detentor de grande biodiversidade. A introdução de germoplasma vegetal no país é um processo dinâmico utilizado para se obter variedades mais produtivas, resistentes a pragas e adaptadas às nossas condições edafoclimáticas. Esta atividade permitiu que, nas últimas décadas, muitas culturas exóticas fossem domesticadas e o país passasse da condição de importador para exportador de diversos produtos agrícolas (Marinho, 2001). Dentro desse universo, a cultura da batata, que é originária dos Andes, foi introduzida no Brasil, adaptada e hoje ocupa um lugar de destaque, sendo a hortícola mais plantada e consumida no país, representando na cadeia produtiva, um valor aproximado de um bilhão de dólares/ano. A produção mundial de batata é de 310 milhões de toneladas em 19 milhões de hectares e o Brasil produz, aproximadamente, dois milhões de toneladas em $100 \mathrm{mil}$ hectares (Shimoyama \& Miranda, 2004). Diversos programas de melhoramento estão sendo desenvolvidos no Brasil procurando adaptar novas cultivares introduzidas às nossas condições edafoclimáticas aumentando a produtividade e a resistência a pragas e doenças. Esse germoplasma de batata, embora de grande importância para a agricultura brasileira, pode trazer pragas exóticas e/ou quarentenárias para o Brasil 
(Marinho et al., 2001). Para evitar a entrada e disseminação dessas pragas no país, todo germoplasma de batata deve ser analisado por um laboratório credenciado pelo Ministério da Agricultura, do Abastecimento e da Pecuária (MAPA) (Instrução Normativa de $\mathrm{n}^{\circ} 1$ de 15 de dezembro de 1998). Em 2002, o MAPA credenciou a Embrapa Recursos Genéticos e Biotecnologia (Cenargen) como Estação Quarentenária nível I, (Portaria № 11 de 15 de fevereiro de 2002).

Em 2003, o Laboratório de Quarentena do Cenargen recebeu para análises fitossanitárias, 40 acessos de germoplasma de batata, com 5 tubérculos, em média, cada acesso, procedentes da França. Esse material faz parte de um projeto de cooperação entre Centros da Embrapa e a Associação de Produtores de Batata da França, e será utilizado em programas de melhoramento no sul do país. Todos os tubérculos foram examinados sob microscópio estereóscopio tendo sido observados, em 6 desses acessos, tubérculos apresentando lesões deprimidas, de aspecto encharcado, coloração marrom-arroxeada, casca amolecida, com picnídios negros sobre as lesões (Figura 1A). Após corte dos tubérculos infectados, verificou-se que o seu interior estava totalmente apodrecido, formando cavidades cobertas por micélio cinza e pontos negros com picnídios (Figura 1B). Foram observados, sob microscópio de luz, micélio ramificado septado, marrom claro com picnídios imersos, uniloculares, negros, globosos, com paredes finas, conídios hialinos, unicelulares ou ocasionalmente com um septo, paredes finas, com freqüência gutulados, elipsóides a cilíndricos, de 5,5-10 × 2,5-3,5 $\mu \mathrm{m}$. Estas características morfológicas correspondem ao fungo Phoma exigua var. foveata (Foister) Boerema (Sutton, 1980), praga quarentenária A1 para o Brasil (Diário Oficial da União, Portaria $n^{\circ}$ 038/99, publicada em 26 de outubro de 1999).

Para confirmar a identificação e a patogenicidade do fungo interceptado, foram realizadas inoculações em tubérculos sadios de batata, colhidos na região do Distrito Federal. Para tal, utilizou-se um isolado de $P$. exigua var. foveata obtido de fragmento de tecido lesionado de um dos tubérculos estudados, submetido à assepsia superficial com álcool a $50 \%$ por $1 \mathrm{~min}$, seguido de hipoclorito de sódio a $0,02 \%$ por 2 min e 2 lavagens com água destilada estéril, em meio de cultura BDA (batata-dextrose-agar), incubação por
15 dias sob luz fluorescente contínua, a $28 \pm 2{ }^{\circ} \mathrm{C}$ (Mendes \& Ferreira, 1994). Discos da cultura pura do fungo em BDA, foram inoculados no centro da superfície interna de tubérculos cortados ao meio e colocados dentro de caixas tipo "gerbox", envolvidos com sacos plásticos para formar câmara úmida. Após o terceiro dia da inoculação foram observadas lesões necróticas nos tubérculos inoculados (FIG 1C), evoluindo o sintoma até o oitavo dia. O fungo foi reisolado dessas lesões, em BDA, confirmando a identificação do patógeno.

O fungo $P$. exigua var. foveata é conhecido como causador da gangrena em Solanum tuberosum L. e, ocasionalmente, encontrado em outras plantas dentro ou perto das lavouras (Rich, 1981; Smith et al., 1997). A taxa de crescimento deste fungo é similar à de P. exigua var. exigua (presente no Brasil) e se caracteriza por possuir colônias relativamente uniformes, com massa micelial brancoacinzentada e margens inteiras não lobadas (Sutton, 1980). Este fungo é transmitido através de tubérculos infectados e os picnídios podem sobreviver no solo. A ocorrência de ferimentos nos tubérculos, durante a colheita, classificação e armazenamento predispõe à infecção. Em experimentos, com infecção artificial dos tubérculos, as perdas podem chegar a mais de 60\% (COSAVE, 1993).

Este fungo já foi relatado em diversos países da Europa, entre eles a França, na América do Norte, na África, na Ásia, na Oceania e na América do Sul, na Colômbia, Peru e Venezuela (EPPO, 1996).

Este é o primeiro relato de interceptação de $P$. exigua var. foveata em tubérculos de batata pelo Serviço de Quarentena do Cenargen. Os tubérculos apresentando sintomas da doença foram incinerados. Por se tratar de germoplasma importante para os programas de melhoramento, os tubérculos aparentemente sadios foram tratados com fungicida sistêmico e plantados em quarentenário. Os tubérculos produzidos foram reexaminados e embora não apresentassem sinais ou sintomas do patógeno, foram novamente tratados quimicamente e plantados em quarentenário. A segunda geração de tubérculos foi analisada, tratada e enviada ao melhorista requisitante.

Além de $P$. exigua var. foveata, outros fungos foram detectados no material introduzido, entre eles, Alternaria
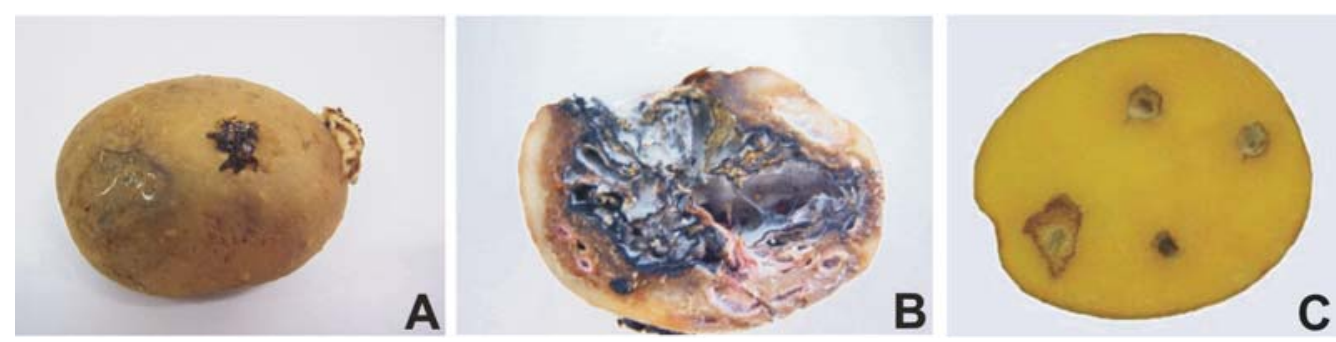

FIG. 1 - A. Tubérculo de Solanum tuberosum (batata) infectado por Phoma exigua var. foveata, com lesões de aspecto encharcado e amolecido, na superfície; B. crateras com micélio branco, no interior; C. sintomas do patógeno, 4 dias após inoculação artificial, em tubérculos sadios de batata. 
alternata (Fr.) Keissl., Helminthosporium solani Durieu \& Mont., Cladosporium sp. e Penicillium sp., todos já relatados no Brasil.

Com esses procedimentos foi possível introduzir o material de batata, tão importante para o estudo de variedades melhores adaptadas às nossas condições de solo e climáticas, e evitou-se a entrada e possível estabelecimento e disseminação de uma praga exótica ao Brasil.

\section{REFERÊNCIAS BIBLIOGRÁFICAS}

COSAVE. Phoma exigua Desm. var foveata (Foister) Boerema y Phoma exigua var exigua Desm. Ficha Cuarentenaria No. 32. COSAVE - Plagas Cuarenterarias, 1993.

EPPO. Phoma exigua. In: Smith, I.M., McNamara, D.G., Scott, P.R. \& Harris, K.M. (Eds.) Quarantine Pests for Europe. Wallingford. CAB International. 1996.
MARINHO, V.L.A. Abertura das Fronteiras entre os países do Cone Sul e a Nova Política Brasileira de Gestão de Riscos Fitossanitários. Série Documentos, Embrapa Recursos Genéticos e Biotecnologia, $\mathrm{N}^{\circ}$ 50. 2001. pp. 1-17.

MENDES, M.A.S. \& FERREIRA, M.A.S.V. Fungos patogênicos detectados em germoplasma vegetal introduzido no Brasil de 1990 a 1992. Fitopatologia Brasileira 19:449-454. 1994.

RICH, A.E. Potato Diseases. New York NY. Academic Press. 1981.

SMITH, I.M., MCNAMARA, D.G., SCOTT, P.R. \& HOLDERNESS, M. Phoma exigua var. foveata. In: Data Sheets on Quarantine Pest. Wallingford. CAB International. UK. 1997. pp. 865-871.

SHIMOYAAMA, N. \& MIRANDA, H.S.F. Defesa Fitossanitária. Revista Cultivar - Hortaliças e frutas. AnoV, n ${ }^{\circ} 25$. Abril $/$ maio 2004. pp 22-23.

SUTTON, B.C. The Coelomycetes: Fungi Imperfecti with Pycnidia, Acervuli and Stromata. Kew, Surrey. Commonwealth Mycological Institute. 1980. 